\title{
Squamous cell carcinoma developing in the scar of Fournier's gangrene - Case report
}

\author{
Chintamani*1, Manu Shankar ${ }^{1}$, Vinay Singhal ${ }^{1}$, JP Singh $^{1}$, Anju Bansal ${ }^{2}$ and \\ Sunita Saxena ${ }^{2}$
}

Address: ${ }^{1}$ Department of surgery, Indian Council Of Medical Research (ICMR), Vardhman Mahavir Medical College, Safdarjang Hospital, New Delhi 110023, India and 2Tumor Biology Lab, Indian Council Of Medical Research (ICMR), Vardhman Mahavir Medical College, Safdarjang Hospital, New Delhi 110023, India

Email: Chintamani* - chintamani7@rediffmail.com; Manu Shankar - drmanu@rediffmail.com; Vinay Singhal - drvinaysinghal@hotmail.com; JP Singh - manu@scientist.com; Anju Bansal - mrinal5@rediffmail.com; Sunita Saxena - sunitasaxena@yahoo.com

* Corresponding author

Published: 27 April 2004

BMC Cancer 2004, 4:16
Received: 15 December 2003

Accepted: 27 April 2004

This article is available from: http://www.biomedcentral.com/I47I-2407/4/16

(C) 2004 Chintamani et al; licensee BioMed Central Ltd. This is an Open Access article: verbatim copying and redistribution of this article are permitted in all media for any purpose, provided this notice is preserved along with the article's original URL.

\begin{abstract}
Background: Squamous cell carcinoma of the scrotum is rare and its development in the scar of Fournier's gangrene is still rarer.

Case presentation: A 65-year-old gentleman presented with a small non-healing ulcer developing on right hemi-scrotum two years after the treatment for Fournier's gangrene. On histological examination it was found to be squamous cell carcinoma. He was successfully managed by surgery in the form of wide local excision and ilio-inguinal lymph node dissection followed by adjuvant radiotherapy and chemotherapy.
\end{abstract}

Conclusions: Squamous cell carcinoma can develop in the scar of Fournier's gangrene after a long delay, which differentiates it from other scar carcinomas or Marjolin's ulcer.

\section{Background}

Squamous cell carcinoma (SCC) developing in the scar of Fournier's gangrene is rare and has only been described once by Schneider et al [1]. Various other cancers however have been found to be associated with the Fournier's gangrene like colonic cancer, lymphoma, multiple myeloma etc [2,3]. Fournier's gangrene is necrotizing fascitis involving the perineum with occasional extension up the abdominal wall. The usual organism is an anaerobic streptococcus synergistic with some second organism. Early therapy in the form of debridement of dead tissue, intravenous broad-spectrum antibiotics are recom- mended. The skin cover is obtained either by primary closure of the wound or skin grafting [1-3].

Scar carcinoma developing in a chronic scar following burns has been described in the literature as Marjolin's ulcer, however the time lapse before the development of this carcinoma in a chronic scar is considerably longer and sometimes may be up to 50 years $[4,5]$. Squamous cell carcinoma is a neoplasm of the keratinising cells that show malignant characteristics including anaplasia, rapid growth, local invasion and metastatic potential. The treatment recommended for SCC is surgery in the form of wide 


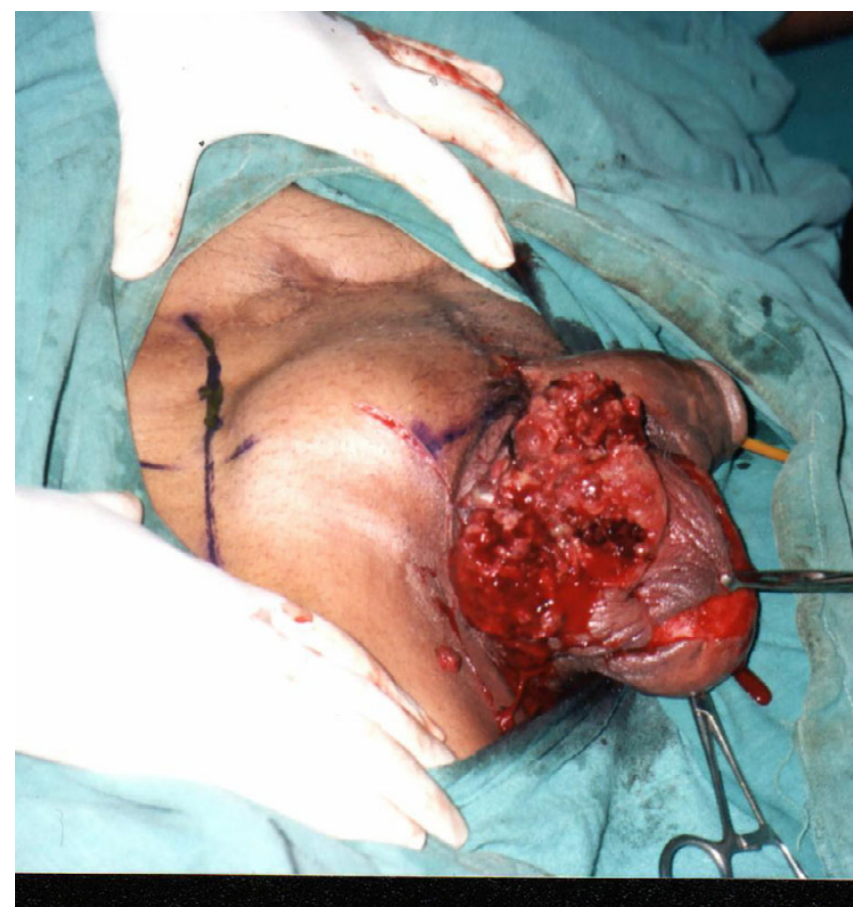

\section{Figure I}

The clinical and preoperative picture showing the ulceroproliferative lesion on the right side of the scrotum. The healed scar of previous debridement done for necrotizing fascitis on the anterior abdominal wall can also been seen.

local excision and block dissection of the draining lymph nodes [6-9].

\section{Case presentation}

A 65-year-old non diabetic and otherwise healthy retired bank clerk was treated at our tertiary centre 24 months previously for Fournier's gangrene involving the right scrotum with necrotizing fascitis extending on to the right lower anterior abdominal wall. He was managed by debridement, split thickness skin grafting of the scrotum and primary closure of skin on the lower abdominal wall. The wound healed satisfactorily after three months of treatment and the follow up was satisfactory.

Two years following his discharge from the hospital the patient was referred to our tertiary centre for a small nonhealing ulcer developing on the right hemiscrotum. The ulcer was increasing in size rapidly and bleeding on touch with a foul smelling discharge. Examination revealed a healthy, well-nourished patient with vitals within normal limits (Pulse: 80/mt, BP: 130/78 mm). He had no bowel or bladder complaints.
There was a $6 \times 7 \mathrm{~cm}$, fungating, ulcero-proliferative growth with everted edges on the right hemiscrotum, which was fixed to the underlying tissues (Fig. 1). The scar on the left hemiscrotum and the anterior abdominal wall was supple and well healed. Inguinal group of lymph nodes on the right-hand side (both the horizontal and vertical chain) were enlarged, hard and mobile. All the other systems were clinically normal. Routine investigations including hemogram (Hb: $13 \mathrm{gm} \%$, total counts: $6000 / \mathrm{cmm})$, blood sugar, kidney function tests, liver function tests and urine examination were essentially within normal limits. X-ray chest and electrocardiogram were also normal. Ultrasonographic examination and contrast enhanced computed tomography of the abdomen did not reveal any abnormality except the enlarged iliac and inguinal group of lymph nodes on the righthand side. Bladder, kidneys and the left hemiscrotum were normal.

The patient was put on antibiotics (third generation cephalosporin, cefotaxime $1 \mathrm{gm}$ intravenously 12 hourly) and provided local wound care using antiseptic dressings of iodine preparations (Betadine). General care in the form of adequate nutrition and hydration was also provided. The incisional biopsy taken from the ulcer edge revealed a poorly differentiated squamous cell carcinoma of the scrotum (there were highly anaplastic, rounded cells with foci of necrosis and dyskeratosis). The patient was prepared for surgery and a wide local excision amounting to right hemiscrotectomy and placement of the right testes in left hemiscrotum through the median raphe was done (Fig. 2). Right ilio-inguinal block dissection was performed en bloc i.e. the lymph nodes were removed in continuity with the primary tumour (Fig. 3).

The histopathological examination of the resected specimen was suggestive of poorly differentiated squamous cell carcinoma of the scrotum with marked nuclear atypia throughout and little evidence of keratinisation particularly in the deeper portions. The cells were rounded, polyhedral and had eosinophillic or clear cytoplasm (Fig. 4). The resected margins were microscopically free from the tumour (R0 resection). Six out of twelve inguinal lymph nodes removed showed metastases.

The patient made an uneventful recovery and was discharged on the tenth postoperative day. He subsequently received adjuvant radiotherapy (dosage: $60 \mathrm{~Gy}$ in fractionated doses) and four courses of combination chemotherapy (Methotrexate, Bleomycin and Cisplatinum in standard doses). He was on a regular follow up and made satisfactory progress. Two years after his surgery the patient had an attack of inferior wall myocardial infarction (MI) involving three vessels for which he was 


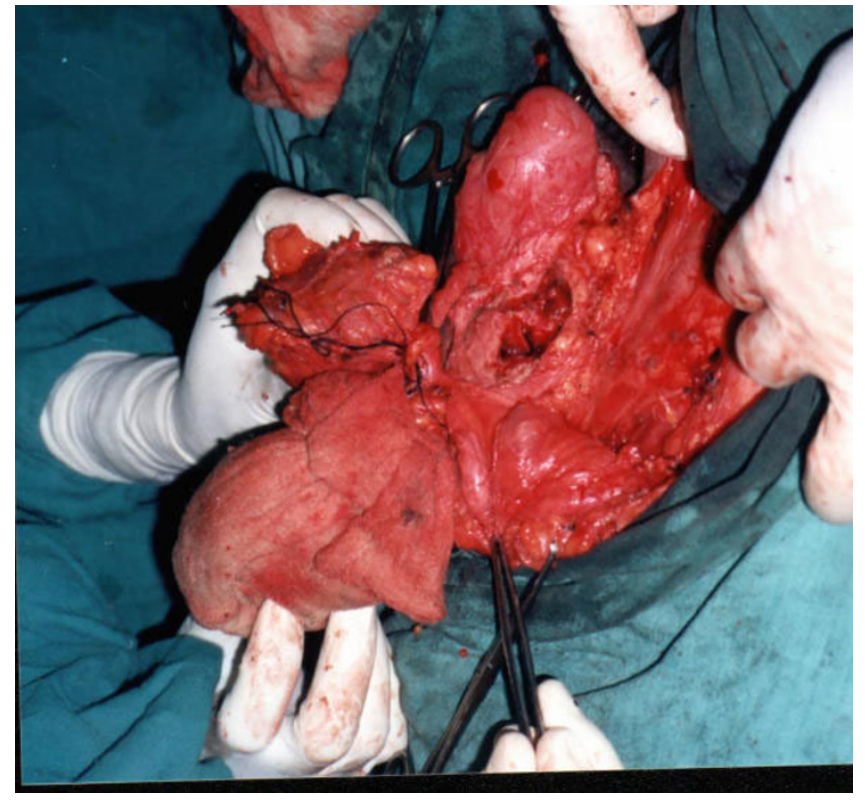

Figure 2

Wide local excision completed and the right testes can be seen at 12 'o clock position about to be placed in the contra lateral scrotum through an opening in the median raphe.

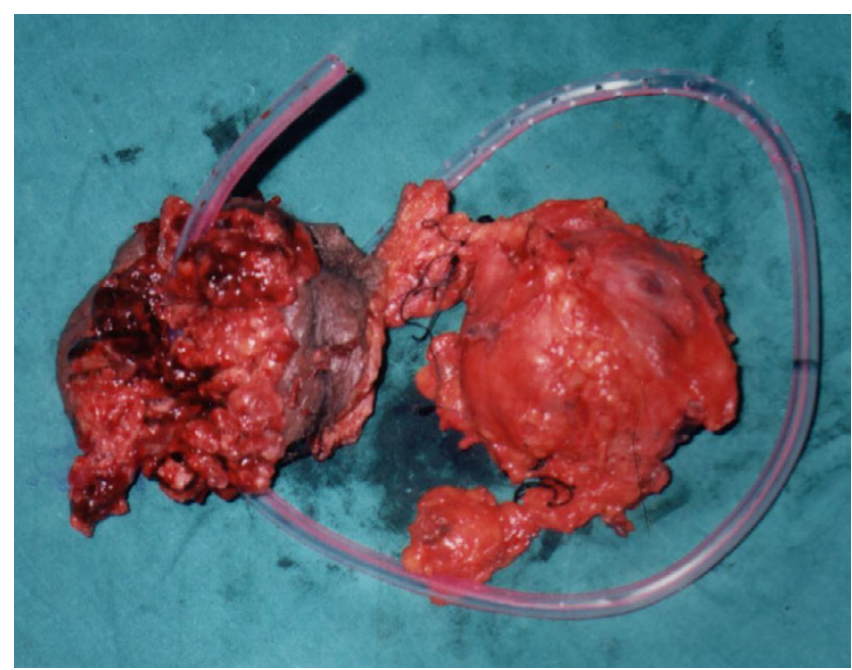

Figure 3

The resected specimen showing the excised Primary lesion along with lymph nodes (en bloc specimen).

managed by the interventional cardiologist but succumbed to a subsequent attack of MI within two months.

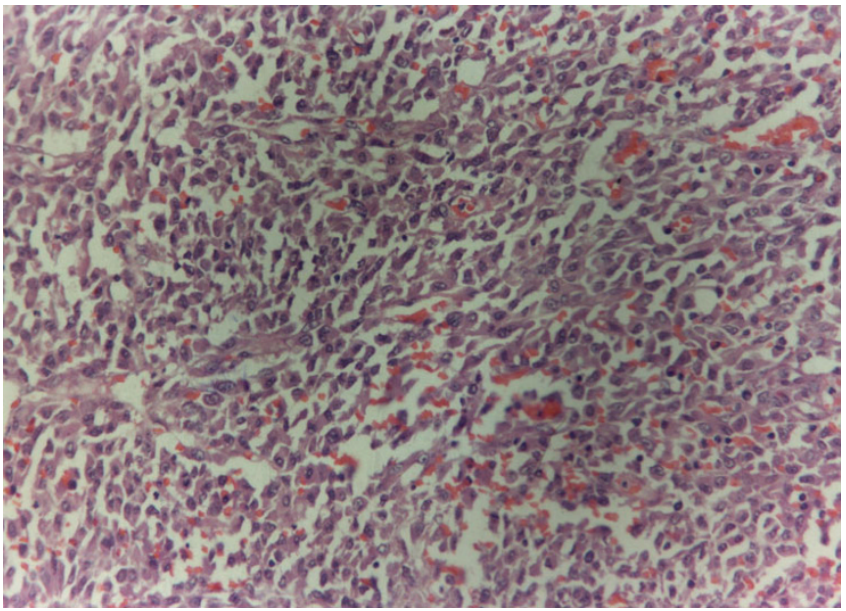

\section{Figure 4}

Photomicrograph showing poorly differentiated squamous cell carcinoma with a high mitotic index and densely staining anaplastic cells

\section{Conclusions}

Since the description of squamous cell carcinoma in chimney sweeps by Percival Pott in the year $1775[5,6]$, soot-related cancer of the scrotum and penis has become anecdotal. This was amongst the first described environmental causes of cancer. Scrotal carcinomas may also occur as a result of non-specific factors such as poor hygiene and chronic irritation, rather than industrial exposure alone [6-8]. This may be partially explained by the similarity in the mechanism of formation of scars by fibrosis and tumorogenesis [7,8]. Scar carcinomas like Marjolin's ulcer and the carcinoma developing in the scar of Fournier's gangrene may also be explained by this similarity in the mechanism.

The prognosis of scrotal carcinomas depends upon the stage and the grade at presentation therefore the significance of early diagnosis for prolonging the survival in a patient of squamous cell carcinoma cannot be overemphasized. High-grade tumours usually have positive lymph node metastases, which carry a grave prognosis [712]. Marjolin's ulcer, a scar carcinoma commonly observed in chronic burn scars is usually slow growing but may also behave aggressively in the form of local recurrence, along with lymph node metastases if the normal tissue is infiltrated. Classically the latency in some cases may extend up to 50 years $[4,5]$.

The most significant predictor of survival in patients with squamous cell carcinoma of the scrotum is age, stage and histological grade at the time of initial diagnosis therefore a high index of suspicion to make an early diagnosis is 
mandatory in order to improve survival. Diagnosis is established by biopsy and the primary modality of therapy is surgery in the form of wide local excision with a safe margin of 3-5 cm in order to achieve R0 resection (microscopically free margin) along with ilio-inguinal block dissection on the affected side $[7,8]$. The wide local excision in some patients may leave large defects amounting to hemiscrotectomy and the testes on the affected side may either have to be sacrificed for non availability of accommodation or translocated to the contra lateral hemiscrotum facilitating closure of the surgical wound and preservation of testes, as was done in the reported case [9].

The neo-adjuvant therapy (both chemo- and radiotherapy) has also been recommended to downstage (reduction in the tumour size and lymph node status thus improving the stage of the disease) a very large lesion in order to achieve Ro resection [10,11]. Adjuvant radiotherapy and combination chemotherapy in the form of four courses of (Methotrexate, Bleomycin and Cisplatinum) is also recommended to achieve a better disease free survival [12]. The prognosis in squamous cell carcinomas depends on various factors like age of the patient, size, grade and stage of the tumour and the adequacy of surgery $[7,8]$.

\section{Authors' contributions}

$\mathrm{CM}$, the principal and corresponding author was the main operating surgeon in charge of the case and prepared the manuscript. MS was the first surgical assistant and the registrar in charge of the case. VS and JP were the postgraduates and second and third surgical assistants. They contributed towards preparation of the manuscript. AB and SS were the histopathologists and contributed to the histopathological details of the manuscript.

\section{Acknowledgement}

Written consent for publication of the case was obtained from a relative of the patient.

\section{References}

I. Schneider PR, Russell RC, Zoo EG: Fournier's gangrene of the penis: a report of two cases. Ann Plast Surg 1986, I 7:87-90.

2. Yumura Y, Chiba K, Saito K, Hirokawa M: Fournier's gangrene in a patient with malignant lymphoma: a case report. Hinyokika Kiyo 2000, 46:735-7.

3. Veljkovic R, Milosevic P, Stojanovic S: Fournier's gangrene associated with carcinoma of the colon. Med Pregl |998, 5 I:35I-4.

4. Garzon R, Burgos EB, Garzon FL, Cippitelli L, de Cabalier ED, Cabalier LR: Marjolin ulcer. Rev Fac Cien Med Univ Nac Cordoba 200I, 58:93-7.

5. Sabin SR, Goldstein G, Rosenthal HG, Haynes KK: Aggressive squamous cell carcinoma originating as a Marjolin's ulcer. Dermatol Surg 2004, 30:229-30.

6. Gerber C, von Hochstetter AR, Schuler G, Hofmann V, Rosenthal C: Penis carcinoma in a young chimney sweep. Case report 200 years following the description of the first occupational disease. Schweiz Med Wochenschr 1995, I 25: I201-5.

7. Futter NG: Scrotal cancer: deja vu. Can J Urol 1998, 5:558-559.

8. Polyak L, Czvalinga I, Frang D: Primary carcinomas of the scrotum - 5 cases. Z Urol Nephrol 1987, 80:455-8.
9. Arango O, Bielsa O, Lorente JA, De Leon E, Mas AG: Hemiscrotectomy with contralateral testicular transposition for scrotal cancer. J Urol 2002, 4:1406-7.

10. Friedman R, Hanson S, Goldberg LH: Squamous cell carcinoma arising in a Leishmania scar. Dermatol Surg 2003, 29: I |48-9.

II. Harder Y, Erni D, Banic A: Squamous cell carcinoma of the penile skin in a neovagina 20 years after male-to-female reassignment. Br J Plast Surg 2002, 55:449-5I.

12. Arai Y, Kinouchi T, Kuroda M, Usami M, Kotake T: A case of scrotal cancer with inguinal lymph node metastasis treated by multidisciplinary modalities including chemotherapy with methotrexate, bleomycin and cisplatin. Hinyokika Kiyo I997, 43:683-5.

\section{Pre-publication history}

The pre-publication history for this paper can be accessed here:

http://www.biomedcentral.com/1471-2407/4/16/prepub
Publish with Biomed Central and every scientist can read your work free of charge

"BioMed Central will be the most significant development for disseminating the results of biomedical research in our lifetime. " Sir Paul Nurse, Cancer Research UK

Your research papers will be:

- available free of charge to the entire biomedical community

- peer reviewed and published immediately upon acceptance

- cited in PubMed and archived on PubMed Central

- yours - you keep the copyright

Submit your manuscript here:

http://www.biomedcentral.com/info/publishing_adv.asp
BioMedcentral 